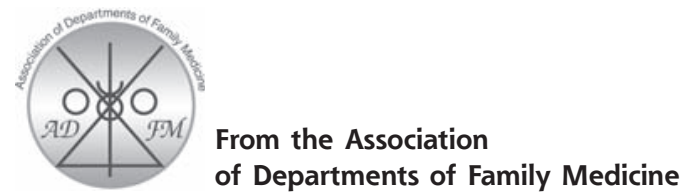

Ann Fam Med 2006;4:373-374. DOI: 10.1370/afm.606.

\section{THE NEXT STEP IN BUILDING FAMILY MEDICINE RESEARCH CAPACITY: FINDING THE WAY FROM FELLOWSHIP}

The future of family medicine depends on a thriving research enterprise that requires a clear vision, commitment, and investment of resources. We have made great progress. A recent survey of departments identified approximately 400 family medicine faculty with external funding (not including Title VII); these faculty are making significant contributions to creating new knowledge and are publishing with increasing frequency. ${ }^{1}$ Given our success in building research capacity, ADFM believes that the most important question is no longer, "how do we get faculty interested in research? " or "how do we obtain research fellowships?" but, instead, "how do we help young and mid-career researchers make the transition to sustained independent funding?" This is particularly important in the current context of flat NIH budgets, diminishing institutional resources, and departments' increasing reliance on clinical income.

What doesn't work is clear. Setting up single researchers in every department-giving them the title of "research director", a fraction of their time for scholarly activities and little else-will not drive us forward. Similarly, the days of the "lone ranger" are over. Departments of family medicine cannot afford solitary investigators conducting their own research in a vacuum. Today's funded research is almost always done in teams. Finally, developing researchers "on the cheap" is a recipe for failure. The minimum typical outlay for developing new researchers is $\$ 300,000$ and often more; even with that investment, many faculty do not gain independent R01 or equivalent funding. Substantial, ongoing departmental investment is necessary.

What are the proper initial conditions necessary to make the transition from research fellow to Principal Investigator (PI) in a federal grant? Release from other obligations needs to be substantial and prolonged, but exactly how much and how it is counted is unclear and varies across departments. Borrowing the model from the basic sciences and $\mathrm{K}$ awards, many fellows expect up to $80 \%$ time for several years, while the Robert Wood Johnson Foundation Generalist Physician Faculty Scholars Program asked for 50\% release time. Given the lack of a clear "best practice", what should departments set as desirable goals for new research faculty? First, fellowship directors must emphasize publications and grant writing experience, including development of a career award proposal. Researchers should hit the ground running producing publications and grants. Second, we must explore models of faculty positions that provide substantial research-focused time (40 to 50\% or greater), while not eliminating clinical and teaching roles. Department chairs and their research faculty must define and measure research success. This might include benchmarks for sustained grant support, publications, research leadership and mentoring. We also need to look beyond the standard 2- to 3-year period to secure funding for a researcher.

Institutional or individual $\mathrm{K}$ awards can help. They provide up to 5 years of support for young faculty. Preparing proposals provides junior faculty with an important opportunity to identify mentors and develop a plan for pilot data, publications and grants. However, $\mathrm{K}$ awards are increasingly competitive and most faculty with $\mathrm{K}$ awards do not make the transition to obtaining R01s. Moreover, the $80 \%$ protected time model is not realistic for most of our faculty: to win 2 to 3 R01s by year 5 would be unusual!

We need to look also to other models of developing young researchers. In the basic sciences, there is often an apprenticeship or post-doctoral time where the newly trained learn the basic processes needed for success. While graduate school and fellowship is a time to learn methods, the period post-fellowship is a time to learn "how to play the game." This learning is best done under the guidance of an experienced mentor, someone who is funded and has a funded trajectory of inquiry. This approach often requires that the junior faculty member delay pursuing an independent research question and become a member of the mentor's team. ${ }^{2}$ In this way the junior faculty member has an opportunity to benefit from available research data, co-author manuscripts and become a co-investigator. This approach allows learning the art of grant-writing through cycles of submission and resubmission with their mentor.

Outsourcing mentorship is also a possibility. Good quality mentorship is critical to the development of young researchers, but mentors do not necessarily need to be members of the department of family medicine (eg, a cancer center, or a health services research center). "Lending out" our scarce future researchers in anticipation that they will gain necessary skills and return to us may be risky. One approach that has been piloted in some FM departments is to have dual mentorships both inside and outside departments of family medicine. This has helped foster an FM faculty iden- 
tity while providing research training and fostering transdisciplinary relationships.

We look forward to more dialogue among departments and faculty members.

Carlos Roberto Jaén, MD, PbD

Jeffrey Borkan, MD, PbD

Warren Newton, MD, MPH

and the Association of Departments of Family Medicine

\section{References}

1. Pathman DE, Gamble G, Thaker S, Newton WP. A metric of progress for family medicine research. Ann Fam Med. 2005;3:88-99.

2. Katerndahl DA. Directing Research in Primary Care. Oxford: Radcliffe Publishing; 2006.

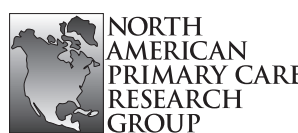

ARE From the North American GROUP Primary Care Research Group

Ann Fam Med 2006;4:374-375. DOI: 10.1370/afm.607.

\section{VARIATION IN THE DESIGN AND PERFORMANCE OF PRIMARY CARE: INTERNATIONAL PERSPECTIVES}

Some of those who debate health care reform in the United States often point to the experience of other countries as justification for keeping things more or less the same, while others point to those same countries as potential models for a radically redesigned US system. That debate was energized and enlightened by a marvelous forum on the comparative performance of primary care in several countries at the 2005 NAPCRG Annual Meeting held in Quebec City, Quebec, Canada last fall. A highlight of this forum was the presentation by Marie-Dominique Beaulieu, MD, MSc, of the Canadian Health Service Research Foundation's analysis of the correlates of performance with various structural models of primary care. ${ }^{1}$

The research team examined the organizational structure of 28 distinct models of primary health care delivery in a large number of industrialized nations. From this analysis, they derived 4 archetypal organizational models, the key characteristics of which are summarized below:
1. Professional contact model - care by FPs solo or in groups; little/no association with other health care professionals; fee-for-service; IT is for internal use only; no formal attention to continuity; no formal integration of services with other providers; dominant model in the United States, Canada, and Belgium

2. Professional coordination model - care by FPs and nurses; capitation or capitation plus fee-for-service $_{i}$ formal attention to continuity; IT integrates with other sources of health care service, nurse liaison helps integrate health care services; dominant model in the United Kingdom, Denmark, The Netherlands, United States (HMO staff model)

3. Integrated community care model - population care provided by health care centers linked with IT to other providers serving same population; continuity assured by team; availability of care at all times; full scope of care assured; found in some provinces in Canada

4. Non-integrated community care model - health care center focus and full range or services, but no IT or other mechanisms to integrate services with other providers; services not available at all times; no formal mechanism to ensure continuity; found in some provinces in Canada.

These organizational models were evaluated according to 6 basic performance criteria for primary health care service:

1. Effectiveness

2. Productivity (the efficiency of service delivery)

3. Accessibility

4. Continuity

5. Quality (the appropriateness of care from consumer and provider perspectives)

6. Responsiveness (patient-centeredness)

Table 1 portrays the 4 basic delivery models and their rank order for each of the 6 performance criteria.

This analysis suggests that the integrated community model is the most generally desirable form when all performance characteristics are taken into account. It also suggests that the dominant model in the United States, professional contact, is highly accessible (for those with insurance) and responsive, but relatively ineffective, inefficient, and of mediocre quality. Furthermore, the purported superiority of the professional contact model on these 2 dimensions (at least as it is

Table 1. Performance Characteristics of Primary Care Models

\begin{tabular}{lcccccc}
\hline Model & Effectiveness & Productivity & Accessibility & Continuity & Quality & Responsiveness \\
\hline Professional contact & 4 & 4 & 1 & 3 & 3 \\
Professional coordinated & 3 & 2 & 1 & 4 & 3 \\
Integrated community & 1 & 1 & 3 & 1 & 1 \\
Nonintegrated community & 2 & 2 & 4 & 3 & 3 \\
\hline
\end{tabular}

